\title{
NEOLOGISMOS \\ NA MÍDIA \\ EM MEIO \\ À PANDEMIA \\ DA COVID-19'
}

\section{NEOLOGISMOS REPORTADOS EN LOS MEDIOS RELACIONADOS CON LA PANDEMIA DE COVID-19}

\author{
NEOLOGISMS REPORTED IN THE MEDIA RELATED TO THE COVID-19 PANDEMIC
}

Fernando Moreno da Silva*

Jorge Sobral da Silva Maia**

Universidade Estadual do Norte do Paraná

RESUMO: Diante da pandemia provocada pelo novo coronavírus (Sars-CoV-2), causador da doença denominada Covid-19, o mundo assiste a um cenário assustador. Nesse contexto, a sociedade é bombardeada de novas expressões e termos. O objetivo deste trabalho é analisar a renovação lexical relacionada à pandemia por meio dos neologismos divulgados na mídia. O trabalho, de caráter documental-bibliográfico, foi realizado em duas etapas. Primeiro, consultando matérias jornalísticas das mídias tradicional e alternativa, divulgadas entre os meses de janeiro e abril de 2020, que trataram do novo coronavírus. Em seguida, após o levantamento, confirmando ou não, pelo critério lexicográfico, o caráter neológico das unidades mono e poliléxicas selecionadas. Para corpus de exclusão, foram adotados os seguintes dicionários: Michaelis (2015), Houaiss (2009), Aulete (2020), Aurélio (FERREIRA, 2010), VOLP (ABL, 2009). Ao final, foram listados 70 neologismos relacionados ao novo coronavírus, tendo como principais processos a formação sintagmática (31), o empréstimo lexical (11) e a analogia (10).

PALAVRAS-CHAVE: Neologismo. Coronavírus. Covid-19.

RESUMEN: La pandemia causada por el nuevo coronavirus (Sars-CoV-2) creó un escenario aterrador. En este contexto, se crean nuevas expresiones y términos. El objetivo de esta investigación es analizar la creación léxica relacionada con la pandemia a través de los neologismos transmitidos en los medios. Es una investigación documental bibliográfica, realizada en dos etapas. Primero, consultar las noticias de medios tradicionales y alternativos, publicadas entre enero y abril de 2020, relacionadas con el nuevo

\footnotetext{
${ }^{1}$ Este texto apresenta parte de pesquisa de pós-doutorado realizada junto ao PPG-Letras da UFRGS e financiada pelo Conselho Nacional de Desenvolvimento Científico e Tecnológico (CNPq) por meio da bolsa de Pós-Doutorado Sênior (Processo 102106/2019-3).

*Pós-doutorando em Letras pela Universidade Federaldo Rio Grande do Sul (UFRGS). Professor adjunto da Universidade Estadualdo Nortedo Paraná (UENP). E-mail: moreno@uenp.edu.br.

** Pós-doutorado pela UNESP/Botucatu-SP. Professor Associado dos Programas de Pós-Graduação em Ciência Jurídica e em Educação da Universidade Estadual do Norte do Paraná (UENP) e do Programa de Pós-Graduação em Educação da UNESP. E-mail: sobralmaia@uenp.edu.br.
} 
coronavirus. Después de la encuesta, confirmamos el carácter neológico de las unidades seleccionadas por el criterio lexicográfico. Para el corpus de exclusión, adoptamos los siguientes diccionarios: Michaelis (2015), Houaiss (2009), Aulete (2020), Aurélio (FERREIRA, 2010), VOLP (ABL, 2009). Al final, enumeramos 70 neologismos relacionados con el nuevo coronavirus. Los principales procesos fueron la formación sintagmática (31), el préstamo léxico (11) y la analogía (10).

PALABRAS CLAVE: Neologismo. Coronavirus. Covid-19.

ABSTRACT: The pandemic caused by the new coronavirus (Sars-CoV-2) created a frightening scenario. In this context, new expressions and terms are created. The objective of this research is to analyze the lexical creation related to the pandemic through the neologisms reported in the media. It is a documentary bibliographic research, carried out in two stages. First, consulting news from traditional and alternative media, reported between January and April 2020, related to the new coronavirus. After the survey, we confirmed the neological character of the units selected by the lexicographic criterion. For exclusion corpus, we adopted the following dictionaries: Michaelis (2015), Houaiss (2009), Aulete (2020), Aurélio (FERREIRA, 2010), VOLP (ABL, 2009). At the end, we listed 70 neologisms related to the new coronavirus. The main processes were the syntagmatic formation (31), the lexical loan (11) and analogy (10).

KEYWORDS: Neologism. Coronavirus. Covid-19.

\section{INTRODUÇÃO}

Na televisão, no rádio, no jornal impresso. No Instagram, no YouTube, no WhatsApp. No telefone, nas conversas, na pescaria. O assunto é sempre o mesmo: coronavírus.

Para frear a disseminação da pandemia da Covid-19, doença causada pelo novo coronavírus, que surgiu em dezembro de 2019 na cidade chinesa de Wuhan, o mundo parou. O temor tomou conta da maioria da população mundial. Países, estados e municípios restringiram a circulação de pessoas e decretaram quarentena para isolar famílias em suas casas. Empresas suspenderam as atividades. Cemitérios com fila para sepultamentos. Falências e desempregos. Autoridades decretando estado de calamidade pública. Mídias com programação especial para cobertura dos fatos. Um novo modo de vida é desenhado pela pandemia.

Em meio a esse cenário devastador, com uma sociedade pautada num único tema, termos e expressões se destacam, sendo convocados sobretudo pela mídia para retratar essa nova realidade, mudando o vocabulário do cotidiano: "coronavírus", "quarentena" "álcool em gel”, "máscara", "isolamento social”, "ensino remoto", etc. Dentre as palavras mais divulgadas, a campeã de aparição é, sem dúvida, "coronavírus" (do lat. corona "coroa" + vírus). A título de curiosidade, esse termo, que é próprio das Ciências Biológicas, não aparece em todos os dicionários. Entre nossos principais dicionários, consta apenas no Aurélio (FERREIRA, 2010), no Aulete (2020) e no VOLP, não sendo registrado no Michaelis (2015) nem no Houaiss (2009).

Quais são as unidades lexicais criadas nesse cenário? Por quais processos elas são formadas? Diante dessas questões, nosso objetivo é analisar como se dá essa renovação lexical pululante na mídia relacionada à pandemia. Como novas formas ou novos sentidos surgem para nomear uma nova realidade - afinal, a variação e a mudança são inerentes ao sistema linguístico, um organismo vivo, dinâmico e expansivo -, partimos da premissa de que as criações lexicais ocorrem naturalmente como parte da evolução da língua. Assim, o método empregado nesta pesquisa é o dedutivo, pois buscamos comprovar esse pressuposto. Por meio do procedimento documental-bibliográfico, realizamos o trabalho em duas etapas.

Num primeiro momento, consultamos matérias jornalísticas ${ }^{2}$ das mídias tradicionais (Folha de S. Paulo, Correio Braziliense, etc.) e alternativas (Repórter Brasil, Carta Maior, blogs, etc.), divulgadas entre os meses de janeiro e abril de 2020, que trataram do novo coronavírus. Após o levantamento da etapa documental, verificamos, empregando o critério lexicográfico para determinar o caráter neológico das unidades mono e poliléxicas selecionadas, se havia ou não o registro delas em thesauri ${ }^{3}$ brasileiros. Para isso, adotamos

${ }^{2}$ Consideramos como matéria jornalística vários gêneros: notícia, manchete, reportagem, coluna, etc.

${ }^{3}$ Entendemos thesaurus (plural em latim: thesauri) como dicionário extenso, com mais de cem mil verbetes. 
como corpus de exclusão os seguintes dicionários: Michaelis (2015), Houaiss (2009), Aulete (2020), Aurélio (FERREIRA, 2010), $\operatorname{VOLP}(\mathrm{ABL}, 2009)$.

No trajeto deste artigo, discorreremos inicialmente sobre os conceitos de neologia e neologismos. Em seguida, sobre os principais processos de criação lexical, como derivação, acronímia e empréstimo lexical. Por fim, analisaremos as novas palavras e expressões surgidas no cenário da pandemia.

\section{NEOLOGIA E NEOLOGISMO}

O léxico é o conjunto de unidades mono e poliléxicas de uma língua, constituindo um sistema complexo, dinâmico e altamente produtivo. Sendo assim, a expansão lexical, por meio da formação de novas palavras ou de novos sentidos às palavras já existentes, lhe é inerente.

O processo responsável pela ampliação lexical é chamado de neologia (neo "novo" + logia "palavra"). A unidade lexical resultante desse processo é denominada de neologismo. Neologia, portanto, é o processo de criação lexical, e neologismo, a unidade criada a partir desse processo. Só é considerada neologismo a unidade que ainda não pertence oficialmente à língua. Como determinar a existência oficial de uma unidade? Quais os critérios para determinar o caráter neológico de uma unidade lexical?

O filtro lexicográfico, por meio do corpus de exclusão (conjunto de dicionários usados para a consulta), é o critério mais adotado para determinar o caráter neológico de uma unidade. As unidades que não estejam registradas no dicionário são consideradas neologismos. O registro delas no dicionário, porém, marca a desneologização da unidade.

Assim, o processo da neologia começa e termina no dicionário, pois este adquire o estatuto de instância de legitimação do léxico, funcionando como um "cartório de registros" (KRIEGER, 2012, p. 19) que concede à palavra sua certidão de nascimento e, consequentemente, a institucionalização dela no conjunto léxico da língua.

\section{PROCESSOS DE CRIAÇÃO DE NEOLOGISMOS}

A língua se vale de muitos mecanismos para a produtividade lexical. Há três processos básicos de formação: (i) neologia vernacular: mecanismos próprios da língua. Segundo Carone (2003, p. 36), os recursos mais férteis para a produção de novas palavras são a derivação e a composição; (ii) neologia por empréstimo: importação de unidades de outras línguas, com formas adaptadas ou não: estresse (de stress), broadcasting; (iii) neologia híbrida: quando unidades são formadas a partir de elementos de línguas diferentes: showmício (inglês show + português comício).

Nesses três processos, a formação de novas unidades lexicais pode ocorrer nos planos de expressão e de conteúdo. No plano de conteúdo, temos a neologia semântica: atribuição de novo sentido à palavra já registrada no dicionário, reutilizando-a com novas acepções, como, por exemplo, salvar (de "resgatar" para "gravar" na informática). No plano de expressão, temos a neologia formal, com o aporte da morfologia lexical que se dedica aos processos de formação de palavras. Há vários processos. Em virtude da limitação de espaço de um artigo, explicaremos abaixo apenas os processos envolvidos nos neologismos relacionados à pandemia selecionados para este trabalho. São eles: composição, recomposição, cruzamento vocabular, derivação (prefixal, sufixal e imprópria), siglação e acronímia, truncação, hibridismo, empréstimo lexical e formação sintagmática e neologia semântica.

\subsection{COMPOSIÇÃO}

União de radicais ou palavras, resultando numa palavra composta, seja por base presa (aero- > aeromoça, foto- > fotossíntese), seja por base livre (banana-maçã, surdo-mudo, salário-família). 


\subsection{RECOMPOSIÇÃO}

Junção de forma reduzida com palavras plenas. Palavras plenas são reduzidas pelo truncamento para, com radicais neoclássicos ressemantizados, formarem novas palavras. Em autodidata, autoatendimento, autoexame, automóvel, o radical auto- significa "eu mesmo, si mesmo”. Entre eles, a palavra automóvel, reduzida a auto-, é recomposta em autopeças, autoescola, autoesporte, autoestrada. Nestas palavras, o sentido etimológico original de auto- ("eu mesmo, si mesmo") é substituído pelo sentido reduzido de automóvel (sinônimo de auto-). Abaixo, na coluna à esquerda, as palavras portam o sentido etimológico do formante auto-. Na coluna à direita, as palavras foram recompostas, com o formante auto- significando automóvel:

Quadro 1: Formativo auto-

\begin{tabular}{c|c}
$\begin{array}{c}\text { COMPOSIÇÃO CLÁSSICA } \\
\text { auto- ("eu mesmo, si mesmo”) }\end{array}$ & $\begin{array}{c}\text { RECOMPOSIÇÃO } \\
\text { auto- (“carro”) }\end{array}$ \\
$\begin{array}{c}\text { autodidata, autoestima, autoimagem, } \\
\text { autoatendimento, autoajuda, autoavaliação, } \\
\text { autoexame }\end{array}$ & $\begin{array}{c}\text { autopeças, autoescola, autoesporte, } \\
\text { autoestrada, autorrádio, autosseguro, } \\
\text { autopista }\end{array}$
\end{tabular}

Fonte: Adaptado de Gonçalves e Andrade (2016, p. 281)

\subsection{CRUZAMENTO VOCABULAR ${ }^{4}$}

Sobreposição de palavras para, cruzando partes delas, formar apenas uma. Ex.: apertamento (apartamento + apertado), brasiguaio (brasileiro + paraguaio), exagelado (exagerado + gelado). Enquanto composição e derivação seguem princípios morfológicos, respeitando o encadeamento linear de radicais e afixos, o cruzamento vocabular segue princípios prosódicos, eliminando segmentos sem preservar constituintes morfológicos.

\subsection{DERIVAÇÃO SUFIXAL}

Acréscimo de sufixo a uma base. Ex.: pianizar (piano + -izar), lulismo (Lula + -ismo), cadernão (caderno + -ão).

\subsection{DERIVAÇÃO PREFIXAL}

Acréscimo de prefixo a uma base. Ex.: pré-ajustar, desfazer, super-rádio, autoassistência.

\subsection{DERIVAÇÃO IMPRÓPRIA ${ }^{5}$}

Mudança gramatical da palavra sem alterar a forma. Ex.: "Os bons serão lembrados" (de adjetivo a substantivo); "O olhar dela me conquistou" (de verbo a substantivo); "O carro custou caro" (de adjetivo a advérbio).

\footnotetext{
${ }^{4}$ Outras designações: amálgama, amálgama de palavra, amálgama lexical, blend, blending, coinage, combinação, contaminação, cruzamento, cruzamento de palavra, FUVES (fusões vocabulares expressivas), mescla lexical, mesclagem lexical, mistura, mot-tiroir, mot-valise, palavra-valise, palavra entrecruzada, palavra mesclada, palavra-síntese, portmanteau, portmanteau word, entre outros.

${ }^{5}$ Outras designações: conversão, hipóstase, translação.
} 


\subsection{SIGLACÃO E ACRONÍMIA}

Redução de nome sintagmático (composto de duas ou mais palavras gráficas) a um conjunto de letras ou sílabas iniciais. Para vários autores $^{6}$, a distinção entre sigla e acrônimo reside na forma como são pronunciadas as unidades reduzidas. Quando a redução apresenta pronúncia alfabética, é chamada "sigla" (ABNT, INSS); quando silábica, é “acrônimo” (UNESP, USP, ONU).

\subsection{TRUNCAÇÃO}

Redução sofrida pela palavra com eliminação de segmentos ou sílabas, sem perda do valor semântico: moto (motocicleta), cine (cinema ou cinematografia), pornô (pornografia), apê (apartamento).

\subsection{HIBRIDISMO}

União de constituintes (radicais, afixos ou palavras) provenientes de línguas diferentes, resultando numa forma híbrida: showmício (show + comício), pizzaria (pizza + sufixo -aria), lobista (lobby + sufixo -ista), wikinovela (wikipedia + novela), funk-se (funk + pronome "se"). As gramáticas incluem nesse tipo de formação as palavras com radicais clássicos: alcoômetro (árabe e grego), burocracia (francês e grego), sociologia (latim e grego).

\subsection{FORMAÇÃO ANALÓGICA ${ }^{8}$}

Construção morfológica espelhada em outra. Ex.: lista branca (de lista negra), enxadachim (de espadachim), bebemorar (de comemorar).

\subsection{EMPRÉSTIMO LEXICAL}

Adoção, por determinada língua, de unidade proveniente de outra língua. Há basicamente cinco tipos de empréstimo:

a) empréstimo não adaptado graficamente: quando a língua receptora usa forma original da língua importada sem adaptação gráfica. Ex.: best-seller, check-up;

b) empréstimo adaptado graficamente: quando a forma estrangeira sofre alteração para se adaptar à ortografia da língua receptora. Ex.: estresse (do ingl. stress);

c) empréstimo traduzido: tradução literal de forma estrangeira. Ex.: cachorro-quente (do ingl. hot dog);

d) empréstimo semiadaptado graficamente: quando numa mesma palavra aparecem morfemas estrangeiros e vernáculos. Ex.: pizzaria (do ital. pizza + sufixo -aria);

e) empréstimo de sentido: emprestar sentido usado em forma estrangeira. Por exemplo, o verbo "salvar" no sentido de "gravar" (do ingl. save = gravar): "vamos salvar o arquivo na pasta".

\footnotetext{
${ }^{6}$ Rodrigues (2016), Araújo (2015), Santiago (2007), Hartmann e James (2001).

${ }^{7}$ Outras designações: abreviação vocabular, clipping, derivação truncada, truncamento, redução, encurtamento.

${ }^{8}$ Outras designações: analogia, criação analógica, neologia intertextual.
} 


\subsection{FORMAÇÃO SINTAGMÁTICA}

Responsável pela formação de unidades polilexicais (formadas por mais de uma palavra gráfica) chamadas "unidades fraseológicas" (UF). Há vários tipos de UF:

a) expressão idiomática: expressão conotativa e fixada pela tradição cultural. Ex.: ou caga ou sai da moita ("Ai meu deus; Agora ou caga ou sai da moita. Agora é pra valer a parada de ir morar em Curitiba”); entrar pelo cano ("Com a crise, o trabalhador vai entrar pelo cano");

b) colocação: combinação recorrente de palavras formada de uma base (ponto de referência) e de uma ou mais unidades lexicais antepostas ou pospostas que qualificam a base $)^{9}$. Ex.: código de barras, vinho tinto, gravemente ferido, deixou a desejar, por favor;

c) provérbio: expressão muito comum na oralidade para transmitir um ensinamento da sabedoria popular. Ex.: Amor com amor se paga; De grão em grão, a galinha enche o papo;

d) termo complexo (ou "unidade fraseológica especializada"): unidade terminológica da linguagem especializada formada de duas ou mais palavras gráficas. Ex.: impacto ambiental, vias biliares, mal de Alzheimer.

\subsection{NEOLOGIA SEMÂNTICA}

Atribuição de novo sentido à palavra já registrada no dicionário, reutilizando-a com novas acepções, como, por exemplo, navegar, de "conduzir embarcação" para "consultar sites na internet".

Após expor os processos de formação de palavras responsáveis pelas criações neológicas identificadas nesta pesquisa, veremos a seguir os neologismos relacionados à Covid-19 que foram divulgados nas matérias jornalísticas.

\section{NEOLOGISMOS RELACIONADOS À COVID-19}

Para apresentar os neologismos e seus respectivos processos, colocamo-los nos seguintes grupos de criação lexical: (i) acronímia, (ii) derivação, (iii) composição, (iv) cruzamento vocabular, (v) truncação, (vi) formação analógica, (vii) empréstimo lexical, (viii) formação sintagmática e (ix) neologia semântica.

\footnotetext{
9 “As colocações são expressões linguísticas formadas por uma base e um colocado, na qual encontramos coocorrência léxico-sintática, ou seja, as palavras que constituem a expressão frequentemente aparecem juntas, dando, inclusive, a impressão de que a combinação se deu de forma natural (correr perigo / perdidamente apaixonado / gravemente ferido / arrumar a cama / tirar a mesa / tomar ar / imprensa marrom / chave mestra / obediência cega / frase feita / condições de pagamento / colocar uma questão / dar um passeio / ter um sonho / prestar atenção / pegar um táxi...)" (MONTEIRO-PLANTIN, 2014, p. 72).
} 


\subsection{ACRONÍMIA}

Coronavírus é um tipo de vírus ${ }^{10}$. A pandemia surgida no final de 2019 na China é causada por um novo coronavírus denominado "Sars-CoV-2", que provoca a doença chamada "Covid-19".

Para a formação desses dois termos (Covid-19, Sars-CoV-2), há três processos envolvidos: empréstimo, acronímia e composição.

O empréstimo lexical existe porque são formados pela redução de expressões inglesas: COrona VIrus Disease ("doença causada por coronavírus") > Covid; Severe Acute Respiratory Syndrome Corona Virus ("síndrome respiratória aguda grave do coronavírus") > Sars$\mathrm{CoV}$.

São acrônimos porque nas reduções há pronúncia silábica, diferentemente da sigla, que possui pronúncia alfabética.

Além da acronímia produzida por empréstimo, a composição também está presente nos termos, pois a redução Covid é combinada com outra redução (2019 > 19), o ano do surgimento e da descoberta da doença: Covid + 19 > Covid-19. O mesmo ocorre com SarsCoV-2 (síndrome + coronavírus + 2). Como assinala o hífen, trata-se de composições por justaposição.

“Trump diz que China sofrerá consequências se país tiver responsabilidade na pandemia da Covid-19.”

"Mortes por Covid-19 nos EUA passam de 40 mil."

"Sprays antissépticos são menos eficazes contra Sars-CoV-2."

"A origem do Sars-CoV-2."

\subsection{DERIVAÇÃO}

Os neologismos vinculados ao novo coronavírus são formados por três tipos de derivação: sufixal (acréscimo de sufixo), prefixal (acréscimo de prefixo) e imprópria (mudança de classe gramatical sem alterar a estrutura formal da palavra):

a) derivação sufixal: negacionismo (negação > negações > negac(i)on + -ismo)

Esse neologismo é formado por derivação sufixal, com o acréscimo do sufixo nominal -ismo à base negação. Para entender esse processo, é preciso considerar a vogal temática da base. Para palavras terminadas em ditongo nasal -ão, a vogal temática pode ficar latente no singular. No plural, ficará patente em três possibilidades:

1) terminação em -ão, mantendo vogal temática, com acréscimo de -s: irmão > irmãos;

2) terminação em - ães, com troca da vogal temática (o > e): pão > pãés;

3) terminação em -ões, com troca da vogal temática $(\mathrm{o}>\mathrm{e})$ : leão $>$ leõe s.

Assim, "negação" se flexiona em "negações", com perda da vogal temática <e > e da desinência <s>, epêntese ${ }^{11}$ de /i/, substituição do diacrítico $^{12}<\sim>$ pela nasal $/ \mathrm{N} /$ e acréscimo do sufixo -ismo, afixo comumente utilizado para denominar doutrinas ou sistemas (marxismo, maniqueísmo). Eis o trajeto formativo: negação > negações $>$ negac(i)on + -ismo.

"Luciano Huck diz que negacionismo no combate ao coronavírus é 'inaceitável'."

\footnotetext{
${ }^{10}$ Além do Sars-CoV-2 (causador da Covid-19), há outros coronavírus: Sars-CoV (identificado em 2002) e Mers-CoV (identificado em 2012).

${ }^{11}$ Há três processos fonético-fonológicos de adição de segmentos sonoros: (i) prótese (ou próstese): inserção de segmento no início da palavra (lembrar e alembrar); (ii) epêntese ("epi"=sobre + "en"=em + "tese"=posição): inserção de segmento no meio da palavra (mês > ['meIs]); (iii) paragoge (ou epítese): inserção de segmento ao final da palavra (top > ['to.pI]). Além dessa tripartição terminológica, costumam adotar os seguintes termos: epêntese interna ou externa (no início e no final) ou epêntese inicial, epêntese medial e epêntese final.

${ }^{12}$ Acento gráfico ou diacrítico é o sinal distintivo que acompanha uma letra.
} 
"O negacionismo e a boa notícia"

b) derivação prefixal:

1) Subnotificação(sub- "abaixo de") e supernotificação (super- "além de")

Os neologismos foram criados pelo acréscimo dos prefixos sub-e super- à palavra já existente notificação.

A notificação (divulgação) do número real de casos de Covid-19 no Brasil tem gerado polêmicas. Frequentemente as autoridades sanitárias são acusadas de divulgar números imprecisos, ora com subnotificação (divulgação do número de casos abaixo do real), ora com supernotificação (divulgação acima do número real). A subnotificação pode ocorrer quando são contabilizados apenas os casos graves de Covid, deixando de fora da estatística os casos leves da doença. Com isso, os casos reais poderiam ser superiores aos números oficiais. Há supernotificação quando mortes provocadas por outras causas (infarto, derrame, aneurisma, etc.) são classificadas como Covid-19.

"MPF cobra explicações do ministro da Saúde sobre subnotificação do coronavírus."

"Doria rebate suposta supernotificação de mortes por coronavírus em SP."

2) Desconfinamento (des- "oposição/negação" + confinamento)

Com o controle da pandemia, países e regiões iniciam o processo de reabertura (fim do confinamento), suspendendo restrições adotadas durante a quarentena. Mas tais medidas são implementadas com prudência, para evitar o retorno da contaminação.

"Coronavírus deixa mais de 250.000 mortos no mundo; desconfinamento prudente em vários países."

"Áustria supera primeira fase de desconfinamento com coronavírus sob controle.

c) derivações prefixal e imprópria:

1) Pós-Covid-19 (pós- "depois")

"O mundo pós-Covid-19"

2) Pós-coronavírus

"É possível imaginar um legado pós-coronavírus?"

3) Pós-pandemia

"Mundo pós-pandemia exigirá um novo papel do Estado."

4) Anticoronavírus (prefixo anti- "contra")

"União Europeia convoca conferência de doadores para vacina anticoronavírus."

5) Antitrabalhador

“O objetivo da mobilização é denunciar o caráter antitrabalhador da MP 905.”

Com relação ao prefixo, cumpre observar que, embora seja considerado uma forma presa posta antes do radical, ele pode funcionar isoladamente na comunicação como forma livre ("há prós e contras com o dólar alto"). Em termos fonológicos, há prefixos (vice- e pós-) que têm acento próprio, com independência prosódica. Por conta disso, Gonçalves (2016) estabelece dois tipos de prefixos: 
a) prefixos composicionais: funcionam fonologicamente como palavras autônomas, com acento: pós-, pré-, pró-, ex-, sub-, contra, anti-, mega-, super-.

b) prefixos legítimos: sílabas átonas que funcionam como pretônicas à base: in-, des-, re- .

Nos quatro neologismos referidos, com exceção de antitrabalhador, além da prefixação houve também derivação imprópria, com mudança gramatical de palavra. O substantivo "coronavírus", por exemplo, se torna adjetivo: "mundo pós-coronavírus". Notemos que não é o acréscimo de prefixo que altera a classe. Gonçalves e Almeida (2014) representam o processo da prefixação pelo seguinte esquema geral:

$\left[\mathrm{X}[\mathrm{Y}]^{\mathrm{y}}\right]^{\mathrm{y}}$

As variáveis X e Y representam sequências fonológicas; a minúscula alceada y, categoria lexical. Esse esquema mostra que o elemento $\mathrm{X}$ preso à esquerda é neutro categorialmente, pois a base $[\mathrm{Y}]$ constitui a cabeça categorial, sendo a classe gramatical das palavras prefixadas idêntica à da base. O prefixo modifica o sentido da palavra, mas a nova formação manterá a classe gramatical da base que recebeu o prefixo.

Isso comprova que não é o prefixo, mas a colocação do neologismo após o substantivo que o altera morfossintaticamente: de substantivo a adjetivo. Os neologismos pós-Covid-19, pós-coronavírus e pós-pandemia qualificam um cenário posterior à pandemia: "mundo pós-pandemia".

\subsection{COMPOSIÇÃO}

\section{1) Necroeconomia}

Em nosso levantamento, houve as seguintes composições (união de palavras ou radicais): Covid-19 (Covid + 19), Sars-CoV-2 (síndrome + coronavírus + 2), álcool-gel, auxílio-emergencial. Além desses (tratados em outras subseções), ocorreu necroeconomia (radical necro- "morto" + economia) ${ }^{13}$ para se referir à prioridade adotada em época de pandemia entre a vida e a economia. A prioridade é salvar vidas, adotando as medidas como o fechamento do comércio, ou salvar a economia, flexibilizando o isolamento para a retomada dos negócios? Quando se nega a humanidade, adotando uma economia perversa, institui-se a necroeconomia.

"Necroeconomia em tempos de pandemia e Bolsonarismo."

\subsection{CRUZAMENTO VOCABULAR}

1) Carentena (carência + quarentena)

A falta de contato físico resultante do isolamento social imposto pela quarentena provocou uma carência afetiva, daí o termo resultante dessas duas palavras, carentena, para nomear a carência na quarentena. A carentena intensificou sites e aplicativos de relacionamentos, nudes e vários problemas psicológicos.

"Carentena: como sobreviver e sair bem desta quarentena da Covid-19."

"Solteira, Cleo desabafa sobre 'carentena': 'Manas, é cada gatilho'."

2) Infodemia (informação + pandemia)

${ }^{13}$ Outras formações com o radical necro-: necrobiose, necrofagia, necrologia, necrotério. 
Como o novo coronavírus atingiu o mundo todo, a mídia é pautada por essa pandemia. Consequentemente, há uma avalanche de informações, misturando notícias falsas e verdadeiras que causam pânico nas pessoas. Essa grande quantidade de informações foi chamada pela Organização Mundial de Saúde (OMS) de “infodemia”.

"Secretário do Ministério da Saúde alerta para infodemia’ sobre coronavírus."

“"Estou sendo vítima da infodemia', diz Regina Duarte."

\subsection{TRUNCAÇÃO}

1) Corona (coronavírus > corona)

Oneologismo corona éformado por truncação, uma redução da palavra "coronavírus" (do lat. corona "coroa” + vírus). A truncação, ao lado de outras reduções, como sigla e acrônimo, é a aplicação da lei do menor esforço para tornar a comunicação mais econômica.

"Temos que lutar contra o corona e contra o vírus do autoritarismo."

"Blogueira mirim viraliza pedindo para Deus 'sumir com o corona'."

"Bozo! O corona não pode parar!"

\subsection{FORMAÇÃO ANALÓGICA}

1) Covard-17 (espelhada em "Covid-19")

Essa formação se refere a Bolsonaro, portador do número 17 nas eleições. Com isso, o enunciador estilisticamente fez uso da forma apocopada de "covarde" [co.var.d], com supressão do fonema vocálico /e/, criando um trocadilho com Covid.

"O Covard-17 e Covid-19: quando a bactéria da covardia se aproveita do vírus da pandemia."

2) Coronavoucher (de "coronavírus")

Embora coronavoucher esteja aqui tipificado como analogia, há também nele os processos de recomposição e hibridismo (originária de línguas distintas). Recomposição porque une a forma truncada e ressignificada corona (de corona "coroa" para corona "coronavírus") a voucher ("vale ou pagamento"). A recomposição consiste na união entre forma reduzida (telefonia > tele) e palavra plena (curso), sendo que a forma reduzida é ressignificada, a exemplo de telecurso, em que o constituinte tele- ("longe" teletrabalho) deixa seu significado etimológico para significar televisão ("aparelho"). Hibridismo pela união da forma aportuguesa corona ao anglicismo voucher. Ao lado do termo coronavoucher, é usada a variante lexical "auxílio emergencial”, como veremos adiante.

"Quem pode receber o 'coronavoucher' de R\$600?"

3) Máscaras já (de “Diretas já”)

Como medida preventiva contra o novo coronavírus, o uso de máscaras passou a ser obrigatório, sujeito à multa, em espaços públicos de diversos estados e municípios. A expressão "máscaras já" foi inspirada em "Diretas já”, movimento ocorrido entre 1983 e 1984 que reivindicava eleições presidenciais diretas no Brasil, algo que só viria a ocorrer em 1989. 
"Máscaras já: amplia-se convicção de que artefatos devem ser obrigatórios contra coronavírus."

4) Solturavírus (de "coronavírus")

Expressão usada para se referir à possibilidade de soltura de presos para conter a disseminação da Covid-19 nas unidades prisionais.

"Prisões, coronavírus e 'solturavírus"

5) Chinavírus (de "coronavírus")

"Bolsonaro ataca governador do DF, mídia e 'Chinavírus'."

"Trump again defends use of the term 'China virus'."

6) PT vírus (de "coronavírus)

"Caiado fala que Brasil já viveu 'PT Vírus' com esquerda no poder."

7) Bolsonarovírus (de "coronavírus", referindo-se ao presidente Jair Bolsonaro)

"Doria diz que Brasil sofre de 'Bolsonarovírus'."

8) Bolsovírus (de "coronavírus", referindo-se ao presidente Jair Bolsonaro)

"Vacina contra o Bolsovírus."

"Conheça os sintomas do bolsovírus, que provoca confusão mental."

9) Comunavírus (de "coronavírus", trocando "corona" por "comuna", de comunismo)

"Chanceler do Brasil surta e 'denuncia' ameaça do 'Comunavírus'."

10) Covidão (de "mensalão", referindo-se ao novo esquema de corrupção oriundo dos repasses de verbas aos estados e aos municípios para combater a pandemia da Covid-19)

"Roberto Jefferson: 'Terão de investigar o escândalo do Covidão após as eleições'."

\subsection{EMPRÉSTIMO LEXICAL}

Os neologismos a seguir elencados foram agrupados por algo em comum: são anglicismos não adaptados graficamente ao português. Permanecem, portanto, na forma original da língua inglesa. Além deles, há também, como já visto, os termos SarsCoV-2 e Covid-19, acrônimos do inglês.

\section{1) Shutdown (“fechamento")}

Trata-se da limitação ou suspensão de atividades comercial e industrial não essenciais. O shutdown é uma das medidas para conter a disseminação do vírus. Nesse caso, as autoridades listam atividades essenciais e não essenciais.

"Bolsonaro sobre shutdown nos transportes: 'vai morrer muito mais gente'."

"Coronavírus: brasileira relata como é viver em 'shutdown' em Miami."

2) Lockdown ("bloqueio total”)

É um confinamento rigoroso e obrigatório em casa que impede a saída de pessoas às ruas, com suspensão total de atividades, podendo ocorrer o fechamento de municípios ou de fronteiras entre países. O lockdown não é recomendação. É lei, sendo imposto à força, com policiamento, fiscalização, multa ou detenção. Trata-se da medida mais rígida de confinamento em pandemia. 
"Netanyahu quer 'lockdown' em Israel para conter avanço de coronavírus."

"Covid-19: Não adianta fazer lockdown no pico da curva de casos, diz Saúde."

"Por coronavírus, Reino Unido estende 'lockdown' por mais três semanas."

3) Live ("ao vivo")

É uma transmissão ao vivo, feita sobretudo pelo Instagram e pelo YouTube. Acabou sendo um recurso muito usado por artistas e pessoas comuns em tempo de quarentena, quando as pessoas ficam em casa. Além de ser um empréstimo lexical, é uma derivação imprópria, porque de adjetivo ("a live concert") passa a substantivo ("veja a live da banda”).

"A era das lives: De Coldplay a Gusttavo Lima, o pop na quarentena."

"Na era do coronavírus, tem muita live para pouco olho na internet."

4) Fintech

Empresa que desenvolve produtos financeiros (empréstimos, seguros, cartões de crédito, etc.) de maneira digital. Além de neologismo por empréstimo, é também um acrônimo, pois é formado a partir da redução da expressão inglesa financial technology ("tecnologia financeira”): FINancial TECHnology > fintech.

"Um novo ciclo para as fintechs pós-covid-19."

"Como fintechs podem ajudar o Brasil a sobreviver à crise do coronavírus."

\section{5) Home office ("escritório em casa”)}

Com a quarentena imposta pelo novo coronavírus, muitas profissionais passaram a trabalhar em casa. Com isso, essa modalidade de trabalho em casa, chamada de home office ou teletrabalho, acabou, por necessidade, sendo adotada por muitas empresas e por profissionais autônomos. Trata-se de um neologismo por empréstimo.

"G1 faz guia do home office em tempo de coronavírus."

"Coronavírus: escritório orienta como adotar home office."

6) Wet market ("mercado molhado")

Diferentemente do "mercado seco", onde há venda de bens duráveis como tecidos, brinquedos e eletrônicos, o wet market é conhecido como um mercado não muito higiênico onde são comercializados produtos perecíveis (carne, frutas e legumes), incluindo animais vivos (aves, roedores, etc.). É apontado como local ideal para o surgimento de doenças infecciosas, pelo contato entre seres humanos e animais.

"Wet markets: o berço do coronavírus."

"Wet' markets chineses são reabertos ofertando cobras, morcegos, ursos, cachorros e mais."

\section{7) Fake news ("notícias falsas")}

As fake news constituem notícias falsas ou boatos divulgados na mídia, muitas vezes de caráter sensacionalista. Embora a expressão tenha surgido antes da pandemia, foi nesse período que ela se intensificou, criando mitos ou falsas esperanças, como tratamentos sem fundamento científico ou curas para a doença.

"Coronavírus: o que é fake news e o que é verdade sobre a transmissão da doença."

"Ceará decide multar quem compartilha fake news na pandemia do coronavírus." 


\section{8) Homeschooling ("educação domiciliar")}

Sistema de ensino em que o aprendizado do aluno é garantido em casa por pais ou por professores particulares, sem frequentar uma instituição de ensino. O homeschooling ainda não é regulamentado no Brasil, mas é uma realidade em outros países. Com a quarentena, o tema voltou a ser discutido.

Entre aqueles que o defendem, a justificativa é de que o ensino tradicional nas escolas é inadequado ou prejudicial à formação da criança por conta da indisciplina, da violência, do bullying e de outros traumas psicológicos sofridos na escola.

Especialistas alertam, porém, que a educação deve ser conduzida por pessoas capacitadas para adequar o conteúdo às idades. Além disso, a educação em casa priva a criança da socialização, também fundamental para o aprendizado da diversidade e de concepções diferentes de sua família.

Sobre essa proposta, cabem algumas questões: com pais e mães trabalhando o dia todo, quem ficará em casa para acompanhar as lições dos filhos? Já que o ensino deve ser conduzido por pessoas capacitadas, como as famílias pagarão um professor particular se grande parte delas ganham até três salários mínimos?

"Regulamentação do homeschooling ganha novo fôlego em Brasília com isolamento por coronavírus."

"Governo vai propor regulamentação do homeschooling."

9) Nude ("nu / despido")

Nude selfie ou simplesmente nude são fotos ou vídeos sensuais divulgados nas redes sociais. A mania foi intensificada em época de isolamento social, quando eventos sociais (baladas, passeios, jogos, etc.) foram substituídos pelo confinamento. Sem possibilidade de encontros, muitos precisam "descarregar a tensão sexual". Além de ser um empréstimo lexical, é também uma derivação imprópria, porque de adjetivo (nude selfie) passa a substantivo (concurso de nudes).

"Nudes contra o tédio na quarentena."

"Ansel Elgort publica nude para incentivar caridade em tempos de coronavírus."

\subsection{Formação sintagmática}

\section{1) Álcool em gel / álcool gel / álcool-gel}

A expressão "álcool em gel” constitui uma formação sintagmática. Embora seja a forma mais usada, apresenta duas variantes: "álcool gel” e "álcool-gel”. Em "álcool gel”, além de uma formação sintagmática variante, há uma derivação imprópria, usando o substantivo "gel” como adjetivo. Em "álcool-gel”, temos uma composição, unindo dois substantivos.

"Brasil amplia produção de máscaras, álcool em gel e ventiladores pulmonares."

"Coronavírus: o álcool gel é eficaz para prevenir a contaminação?"

"OMS indica produto alternativo diante da escassez do álcool-gel."

\section{2) Atividade essencial / serviço essencial}

A quarentena estabelecida pelo governo proíbe aglomeração e restringe a circulação de pessoas. Mas há atividades ou serviços estabelecidos pelo governo como essenciais, ou seja, mesmo com quarentena não podem deixar de funcionar. A Lei $n^{\circ} 13.979$ de 6/2/2020, que dispõe sobre o enfrentamento ao Covid-19, no Art. $3^{\circ}, \$ 11$, assim determina: "É vedada a restrição à circulação de trabalhadores que possa afetar o funcionamento de serviços públicos e atividades essenciais". Alguns dos serviços classificados como 
essenciais pela lei são: assistência à saúde; assistência social; telecomunicações e internet; captação, tratamento e distribuição de água; captação e tratamento de esgoto e lixo; iluminação pública; serviços funerários; etc.

Os dois termos são usados como variantes: atividade essencial ou serviço essencial.

"Consultoria jurídica de advocacia pública é serviço essencial, diz decreto de Bolsonaro."

"Bolsonaro põe imprensa como atividade essencial durante combate à covid-19."

"RJ inclui advocacia no rol de atividades essenciais, com livre locomoção."

"As disputas sobre o que é atividade essencial durante a quarentena."

\section{3) Paciente leve}

Trata-se do paciente em início de quadro clínico, com sintomas leves da Covid.

"Pacientes leves de Covid-19 passarão a ser internados em SP."

"Hidroxicloroquina não elimina novo coronavírus em pacientes leves a moderados."

\section{4) Paciente zero}

Trata-se da primeira pessoa do mundo que contraiu a Covid-19. Estimam que o primeiro caso tenha ocorrido em 17 de novembro de 2019, quando um funcionário do laboratório do Instituto de Virologia de Wuhan (China) contraiu o coronavírus de um morcego. O termo também está sendo empregado para identificar o primeiro paciente de cada país.

"China busca homem que seria o 'paciente zero', 4 meses depois do primeiro caso."

“Paciente zero' da Covid-19 trabalhava em laboratório em Wuhan, noticia Fox News.”

"Afinal, quem é o 'paciente zero’ da Itália?”

\section{5) Grupo de risco}

São as pessoas que correm grande risco de terem complicações caso sejam infectadas pelo vírus, como idosos, diabéticos, hipertensos e aqueles com problemas cardíacos ou pulmonares.

"Um terço dos adultos brasileiros faz parte do grupo de risco do coronavírus."

"Profissionais da saúde do grupo de risco do coronavírus seguem atuando em hospitais do RS."

"Brasil tem milhões em grupo de risco para o coronavírus."

\section{6) Taxa de transmissão}

Número que mostra a capacidade de disseminação do vírus entre as pessoas. No caso do novo coronavírus, estima-se que esse número seja de dois a três, ou seja, cada portador da doença pode transmitir para mais duas ou três pessoas.

"Taxa de transmissão do novo coronavírus tem queda em SC, diz governo."

"Uma das diferenças do coronavírus para os demais está na sua taxa de transmissão elevada."

"Isolamento social reduz taxa de transmissão do coronavírus na Grande São Paulo."

7) Taxa de letalidade

Mostra o número de mortes entre os casos confirmados da doença. 
"Brasil tem a $8^{\text {a }}$ maior taxa de letalidade de coronavírus no mundo."

“Taxa de letalidade no coronavírus na Paraíba é preocupante."

"Nordeste concentra estados com taxa de letalidade por coronavírus acima da média nacional."

8) Caso suspeito, caso confirmado, caso descartado

"Caso suspeito" é o paciente que apresenta sintomas que podem ser da Covid-19 ou que entrou em contato com pessoas infectadas, mas ainda não teve o diagnóstico confirmado por exame. Entre os sintomas estão falta de ar, tosse e febre. Nesses casos, os suspeitos são colocados em isolamento até sair o resultado dos exames. Caso o paciente confirme pelo exame a presença do vírus no organismo, torna-se um "caso confirmado". Quando negativo, torna-se um "caso descartado".

"Uberlândia segue com 4 mortes e 74 casos confirmados de coronavírus, diz Prefeitura."

"Coronavírus: 25 casos confirmados e 930 suspeitos em investigação no Brasil."

"Casos suspeitos de coronavírus no Brasil chegam a 182."

"São Carlos tem mais um caso descartado de COVID-19"

9) Exame rápido / teste rápido

Além do tradicional exame realizado em laboratório para detectar o novo coronavírus, para agilizar o controle da pandemia têm sido aplicados também "testes rápidos" (também denominados de "exames rápidos"). Os exames podem ser realizados em hospitais e clínicas. Enquanto durar a situação de emergência, a Anvisa (Agência Nacional de Vigilância Sanitária) permite que o teste seja realizado também em farmácias, sempre acompanhado de um profissional de saúde. Por meio da coleta de sangue (como um teste de glicemia), o resultado sai em até trinta minutos.

Apesar da praticidade, especialistas alertam que o teste não garante a comprovação absoluta de infecção, tendo índice baixo de acerto, podendo resultar em "falso negativo" ou "falso positivo". Por isso, é recomendado como um recurso auxiliar no diagnóstico, não como definitivo.

"IFMT deve implantar laboratório que faz exame rápido de Covid-19."

"Anvisa discute liberar testes rápidos para Covid-19 em farmácias."

\section{0) Achatar a curva / achatamento da curva}

A curva epidemiológica é uma representação visual do número de pessoas infectadas num determinado período de tempo. Achatar a curva significa retardar a propagação de uma doença. Esse achatamento (diminuição do número de infectados) é alcançado sobretudo com medidas sanitárias, como o distanciamento social.

"Por que e como achatar as curvas do coronavírus."

"Como funciona a matemática do 'achatamento da curva' do coronavírus."

"Coronavírus: achatamento da curva de casos desafoga UTIs em Minas Gerais."

\section{1) Distanciamento social / distância social}

Redução do contato entre as pessoas para diminuir a transmissão do vírus. Entre as medidas tomadas para evitar aglomerações de pessoas estão o fechamento de escolas, a adoção de trabalho em casa (home office), o cancelamento de eventos. Na necessidade de contato, autoridades sanitárias recomendam um afastamento entre as pessoas de ao menos um ou dois metros de distância. Esse afastamento é chamado de distanciamento social ou distância social. Como veremos à frente, distância social é uma expressão usada em Sociologia para se referir à relação de desigualdade entre pessoas ou grupos sociais (entre pobres e ricos). Aqui, portanto, a expressão foi ressignificada como sinônimo de afastamento social. 
"Com UTIs lotadas, Ceará vai prorrogar distanciamento social."

"Medidas de distanciamento social devem durar até 2022, estima pesquisa."

"Uma viagem pelos transportes públicos com a distância social possível."

\section{2) Isolamento social}

Enquanto o "distanciamento social" é uma recomendação dada a todos (infectados ou não) para o contato interpessoal, o "isolamento social" é uma medida preventiva que separa as pessoas infectadas das não infectadas, sem haver contato entre elas. A expressão também varia com "isolamento", unidade já dicionarizada: "Estados podem flexibilizar isolamento". O isolamento pode ocorrer em casa, no hospital ou em outro ambiente. Quando ocorre em casa, é chamado de "isolamento domiciliar".

"Indice de isolamento social se mantém em 49\% em São Paulo."

"Violência física e sexual contra mulheres aumenta durante isolamento social provocado pelo coronavírus."

"Polo industrial de Manaus tem 40 mil trabalhadores em isolamento domiciliar."

\section{3) Isolamento horizontal}

Confinamento em casa de todos os cidadãos, com exceção dos que trabalham em serviços essenciais.

"Estudo do Exército contraria Bolsonaro e apoia isolamento horizontal."

"Ministério Público do Rio defende isolamento horizontal."

\section{4) Isolamento vertical}

Isolamento apenas de pessoas que pertencem a grupos de risco (idosos, diabéticos e portadores de doenças cardíacas ou respiratórias).

"Novo ministro da Saúde criticou abertamente isolamento vertical."

"Isolamento vertical proposto por Bolsonaro pode acelerar contágios por coronavírus."

\section{5) Efeito rebote}

Trata-se do ressurgimento da Covid-19 após isolamento. Para especialistas, como o Dr. Anthony Wong ${ }^{14}$, o ideal para conter uma pandemia não é o isolamento horizontal (para todos), mas apenas o isolamento vertical (para grupos de risco), porque o isolamento total faz com que a doença volte a crescer quando a população retorna às atividades.

Ao contrário das formações sintagmática anteriores (de sentido denotativo), o neologismo "efeito rebote" tem um caráter conotativo, construído por metáfora. "Rebote" é um termo esportivo usado no basquetebol e no futebol para se referir ao retorno da bola ao jogo depois de bater na cesta ou na trave (o jogador aproveitou o rebote e marcou).

"O fundador da Eurasia especula sobre um efeito "rebote" na escalada do Covid-19."

"Especialista alerta para efeito rebote após fim de isolamento."

"No nosso inverno há a possibilidade de efeito rebote ou "segunda onda" - enfatiza o pneumologista."

\footnotetext{
14 “De acordo com Wong, a quarentena agora fará com que daqui dois meses o Brasil tenha uma nova fase de contágio. 'Não é teoria, são modelos matemáticos. Você 'sequestra' o povo, eles carregam o vírus e quando você libera essas pessoas terão contato com quem não teve e volta se ter uma nova onda de casos, chamado de rebote, o ressurgimento da doença”' (MARQUES, 2020).
} 
16) Vala coletiva

Com o número expressivo de mortes provocadas pela Covid-19, alguns cemitérios sepultam vários mortos numa única cova. Diferentemente da "vala comum" (expressão já dicionarizada), uma cova com vários corpos sem identificação, a "vala coletiva" mantém distanciamento entre caixões e identificação das sepulturas.

"Amazonas enterra vítimas da covid-19 em vala coletiva."

\section{7) Hospital de campanha}

Pequena unidade médica móvel (mini-hospital) que cuida temporariamente de pacientes antes de serem transferidos para instalações permanentes de tratamento.

"Morre segundo paciente atendido no hospital de campanha do Anhembi."

\section{8) Auxílio emergencial / auxílio-emergencial / coronavoucher}

Benefício financeiro destinado a trabalhadores informais, microempreendedores individuais, autônomos e desempregados durante o período de enfrentamento da pandemia da Covid-19. O benefício também é chamado de coronavoucher. Embora não seja comum, houve também a aparição da forma composta: "Mulheres que criam filhos sozinhas esperam pelo auxílio-emergencial durante pandemia".

“Governo não poderá antecipar o pagamento da segunda parcela do auxílio emergencial de R \$600."

"Metade dos inscritos tem direito de receber auxílio emergencial de R\$ 600 da Caixa."

\section{9) Cabine de desinfecção}

Equipamento semelhante a um túnel que possui sensor de presença para borrifar todo o corpo com solução que higieniza a roupa.

"Rio vai instalar cabines de desinfecção em locais de grande movimento."

\section{0) Ensino remoto / aula remota / aprendizagem remota}

Entre as medidas para conter a disseminação do coronavírus está a suspensão das aulas presenciais nas escolas. O governo federal publicou no dia $1^{\circ}$ de abril de 2020 a Medida Provisória 934/2020, que dispensa escolas da educação básica e instituições de ensino superior de cumprirem o mínimo de duzentos dias letivos estabelecido pela LDB (Lei de Diretrizes e Bases da educação nacional), mas mantendo a carga horária de oitocentas horas.

Para minimizar o impacto da perda de aulas durante a quarentena e dar continuidade ao conteúdo escolar, essas instituições de ensino têm adotado o "ensino remoto", também chamado de "aula remota" ou de "aprendizagem remota". É um mecanismo que se aproxima da educação a distância $(\mathrm{EaD})$, pela adoção do ensino mediado pela tecnologia, mas se diferenciando do EaD sobretudo por se basear em aulas em tempo real, ministradas pelos próprios professores. Além da transmissão ao vivo, há materiais impressos e digitais fornecidos pelas escolas, conteúdos gravados e plataformas de ensino. Para especialistas, a educação remota deve ser um complemento, não uma substituição das aulas presenciais. Além disso, essa realidade exige uma tecnologia não acessível para todos, sobretudo nas escolas públicas, expondo a desigualdade e a distância entre os mais favorecidos e a grande parte da população.

Os conceitos de homeschooling e ensino remoto estão relacionados, porque em ambos há atividades em casa. Mas a regulamentação desses sistemas é diferente. Enquanto o homeschooling é um sistema a ser implantado permanentemente (trocando a escola pela educação em casa), o ensino remoto é apenas uma medida emergencial a ser adotada durante a pandemia, retornando ao ensino 
presencial na escola após autorização das autoridades sanitárias. Assim, homeschooling é uma prática permanente; ensino remoto, provisória.

"Ensino remoto enriquece o currículo de alunos e professores."

"Professores e pais acionam Justiça contra ensino remoto."

"Posicionamento ABMES sobre aulas remotas."

"CIESB lança estratégias de aprendizagem remota para escolas públicas."

\section{1) Máscara inteligente}

Impulsionados pelo novo coronavírus, fabricantes projetam comercializar máscaras inteligentes para facilitar a vida dos usuários. Com bateria interna e sensores, o produto seria capaz de analisar a qualidade do ar, identificar a presença de vírus e se desinfetar sozinho.

"Xiaomi desenvolve máscara inteligente que se limpa sozinha."

\section{2) Bônus Covid}

Procuradores do estado do Mato Grosso criaram uma ajuda de custo no valor de mil reais, apelidada de "bônus Covid", para complementar os gastos com a saúde. O benefício gerou inúmeras críticas, obrigando o procurador-geral da República a entrar com ação no Supremo Tribunal Federal (STF) para barrá-lo.

"Aras entra com ação no STF para barrar 'bônus covid' a procuradores do MT."

"Procurador-geral de Justiça cria ‘bônus COVID’ de RS 1 mil.”

\subsection{NEOLOGIA SEMÂNTICA}

1) Pandemônio (de "confusão" a "Bolsonaro")

"Bolsonaro é o pandemônio no meio da pandemia."

"O Pandemônio continua ajudando a pandemia a ganhar o jogo!"

A princípio, poderíamos identificar em pandemônio dois processos: analogia e prefixação. Prefixação porque é formada pela junção do prefixo pan- ("tudo/todos") com a palavra plena demônio. Aliás, esse mesmo prefixo é usado em pandemia (pan- "tudo/todos" + demia/demos "povo": o povo inteiro), contrastando com epidemia (prefixo epi- "sobre" + radical demia/demos "povo": sobre um povo/região). Analogia pela semelhança entre pandemia e pandemônio, parecendo, à primeira vista, tratar-se de um trocadilho.

Mas nenhuma dessas hipóteses é correta, porque "pandemônio" é uma unidade já registrada em dicionário. Em sentido figurado, significa "confusão". Entendemos esse sentido pela estrutura morfológica da palavra: pan- "tudo/todos" + demônio. A esse sentido, outra conotação foi adicionada, tratando pandemônio como sinônimo do presidente Bolsonaro.

2) Pandemia (de "doença biológica" a um "mal")

"A pandemia do capitalismo"

O trecho acima considera o capitalismo como gerador de "pandemias", ou seja, de males, como destruição ambiental, exploração de mão de obra, desigualdade social, interdependência entre os países, lobby das corporações, etc. Assim, atribui figurativamente ao termo "pandemia" uma nova significação, de uma doença (caráter biológico) a um malefício (caráter social). 
3) Coronavirus (de um "vírus" a um "problema”)

“'Homem é coronavírus do mundo', diz escritor cubano Leonardo Padura.”

Nessa sentença, o escritor cubano atribui a coronavírus o sentido de "problema” ou "malefício", colocando o homem como causador de danos a sua espécie, como desmatamento, poluição e aquecimento global. Ao termo biológico "coronavírus" (nome genérico de vírus) é acrescentada a conotação de problema social.

4) Distância social (de "diferença socioeconômica" a "afastamento interacional")

"Distância social pode salvar a sua vida ou a de outras pessoas."

"Mantenha a distância social durante o período da covid-19."

A expressão distância social é usada em Sociologia para se referir à relação de desigualdade socioeconômica entre pessoas ou grupos sociais (entre ricos e pobres). Em tempo de pandemia, a expressão foi ressignificada como sinônimo de distanciamento social, ou seja, afastamento entre as pessoas na interação social. O afastamento ou a distância recomendada é de ao menos um metro no contato interacional.

Após a apresentação das formações neológicas, cabem algumas considerações.

Para formação dos setenta neologismos arrolados anteriormente, vários processos foram identificados. Os principais foram formação sintagmática (31), empréstimo lexical (11), analogia (10) e derivação prefixal (8).

A formação sintagmática certamente predominou pelo caráter terminológico das formações. Ao lado dos neologismos de caráter geral (negacionismo, antitrabalhador), abundaram neologismos especializados, ligados às áreas das Ciência Biológicas (Covid-19), da Epidemiologia (paciente zero, isolamento social), da Administração (atividade essencial, serviço essencial) ou dos negócios (home office, live). Os estudos terminológicos têm mostrado a tendência de termos complexos nas comunicações especializadas, "estruturas que costumam alcançar mais de 70\% de uma terminologia" (KRIEGER, 2006, p. 193).

Além da formação sintagmática, outra tendência manifestada nos neologismos foi o empréstimo lexical. O encurtamento de distâncias provocado pela quebra de barreiras da internacionalização em nossa "aldeia global" ${ }^{15}$ também permitiu empréstimos de fenômenos linguísticos, sobretudo do nível lexical, na relação interlingual. Nos últimos anos, houve predomínio do anglicismo, já que, como ressaltou Rocha (2008, p. 70), "na balança comercial do léxico as nações mais fortes são, via de regra, as que exportam mais palavras"; a supremacia da economia estadunidense impulsionou o inglês como língua franca no mundo.

O terceiro processo mais produtivo foi a analogia, que refletiu os termos mais usados no vocabulário cotidiano. Das dez formações, nove foram espelhadas em Covid-19, pandemia e coronavírus (Covard-17, coronavoucher, máscaras já, solturavírus, Chinavírus, PT vírus, Bolsonarovírus, Bolsovírus, comunavírus, Covidão).

É preciso ressaltar que nem sempre uma criação lexical é fruto de um processo exclusivo. Nos termos Sars-CoV-2 e Covid-19, por exemplo, estão envolvidos os processos de empréstimo, acronímia e composição. Em coronavoucher houve analogia, recomposição e hibridismo. Abaixo, um balanço dos processos e dos neologismos:

${ }^{15}$ Expressão criada por Marshall McLuhan e popularizada na sua obra “Os meios de comunicação como extensão do homem”, publicada em 1964. 
Tabela 1: Neologia e neologismos

\begin{tabular}{|c|c|c|}
\hline Processo & Qtde. & Ocorrências \\
\hline formação sintagmática & 31 & $\begin{array}{c}\text { auxílio emergencial, auxilio-emergencial, coronavoucher, ensino remoto, aula remota, } \\
\text { aprendizagem remota, álcool em gel, álcool gel, atividade essencial, serviço essencial, } \\
\text { exame rápido, teste rápido, distanciamento social, distância social, paciente leve, } \\
\text { paciente zero, grupo de risco, taxa de transmissão, taxa de letalidade, caso suspeito, } \\
\text { caso confirmado, caso descartado, achatar a curva, achatamento da curva, } \\
\text { isolamento social, isolamento horizontal, isolamento vertical, efeito rebote, vala } \\
\text { coletiva, hospital de campanha, cabine de desinfecção, máscara inteligente, bônus } \\
\text { Covid }\end{array}$ \\
\hline empréstimo lexical & 11 & $\begin{array}{l}\text { Sars-CoV-2, Covid-19, shutdown, lockdown, live, fintech, home office, wet Market, } \\
\text { fake news, homeschooling, nude }\end{array}$ \\
\hline formação analógica & 10 & $\begin{array}{l}\text { Covard-17, coronavoucher, Máscaras já, solturavírus, Chinavírus, PT vírus, } \\
\text { Bolsonarovírus, Bolsovírus, comunavírus, Covidão }\end{array}$ \\
\hline derivação prefixal & 8 & $\begin{array}{l}\text { subnotificação, supernotificação, desconfinamento, pós-Covid-19, pós-coronavírus, pós- } \\
\text { pandemia, anticoronavírus, antitrabalhador }\end{array}$ \\
\hline derivação imprópria & 7 & $\begin{array}{l}\text { pós-Covid-19, pós-coronavírus, pós-pandemia, anticoronavírus, live, nude, álcool } \\
\text { gel }\end{array}$ \\
\hline composição & 5 & Sars-CoV-2, Covid-19, álcool-gel, auxílio-emergencial, necroeconomia, álcool gel \\
\hline neologia semântica & 4 & pandemônio, pandemia, coronavírus, distância social \\
\hline acronímia & 3 & Sars-CoV-2, Covid-19, fintech \\
\hline cruzamento vocabular & 2 & carentena, infodemia \\
\hline derivação sufixal & 1 & negacionismo \\
\hline truncação & 1 & corona \\
\hline
\end{tabular}

Fonte: Elaboração própria

Guilbert (1975), fazendo referência às linguagens cotidiana e literária, opõe dois tipos de criações lexicais: "neologia denominativa” e "neologia estilística". A denominativa, sem se preocupar com a estética, objetiva nomear produtos, serviços, ideias, etc. para alcançar uma comunicação eficaz própria do cotidiano. Trata-se de uma motivação rotuladora, afinal, o neologismo é a manifestação das mudanças pelas quais passam a sociedade. A neologia estilística, ao contrário, baseada na expressividade da criação poética, manifesta uma forma de percepção do mundo que se aproxima da linguagem literária e dos escritores, garimpando as possibilidades do sistema virtual da língua. Considerando essa tipologia, no nosso levantamento houve tanto neologismos denominativos (álcool em gel, pós-pandemia, negacionismo, home office) quanto estilísticos (Covard-17, Bolsonarovírus, carentena).

Outro aspecto a ser destacado, tanto nos neologismos de caráter geral (antitrabalhador, negacionismo, pandemônio) quanto nos de caráter especializado (Sars-CoV-2, álcool em gel, taxa de letalidade), é a variação (alteração do plano de expressão sem modificar o plano de conteúdo, ou vice-versa). 
A variação do plano do conteúdo caracteriza a polissemia (poli = vários + sema = sentido), que pressupõe unidade lexical com vários sentidos próximos. Houve quatro ocorrências por meio da neologia semântica: pandemônio (de "confusão" a "Bolsonaro"), pandemia (de "doença biológica" a um "mal"), coronavírus (de "vírus" a "problema"), distância social (de "diferença socioeconômica" a "afastamento interacional").

A variação do plano da expressão caracteriza a sinonímia. As variações sonora, morfológica, ortográfica, lexical e sintática são formais (relativas à forma, ao plano de expressão). Em toda variação formal há sinonímia ou parassinonímia ${ }^{16}$. Houve neologismos com três e duas variantes: álcool em gel / álcool gel / álcool-gel ${ }^{17}$; auxílio emergencial / auxílio-emergencial / coronavoucher; ensino remoto / aula remota / aprendizagem remota; atividade essencial/ serviço essencial; exame rápido / teste rápido; distanciamento social / distância social; isolamento social / isolamento. Nas variações formais, houve variante ortográfica (álcool gel / álcool-gel), lexical (auxilio emergencial / coronavoucher) e sintática (álcool em gel / álcool gel).

\section{CONSIDERAÇÕES FINAIS}

Ao final deste trabalho, depois de expor os neologismos presentes na mídia relacionados à pandemia da Covid-19 e seus respectivos processos de formação, confirmamos a premissa de que as criações lexicais são constitutivas do sistema linguístico, pois, como observou Lino (2019), o neologismo é, simultaneamente, como consequência do dinamismo da sociedade do nosso tempo, uma manifestação das evoluções da língua e do conhecimento.

De fato, a dinâmica da sociedade reflete na língua, sobretudo na expansão do léxico, como vimos por meio dos neologismos, que também refletem a evolução do conhecimento, afinal, a maioria dos neologismos apresentados tem caráter especializado. Isso demonstra a importância da ciência nas nossas vidas e o papel dos meios de comunicação como "tradutores" das novidades científicas e tecnológicas ao grande público.

Esse conhecimento especializado acaba refletindo nos processos de formação de palavras, pois há uma tendência nas terminologias - e isso foi confirmado no nosso levantamento, com 31 unidades - das formações sintagmáticas. Como o conhecimento se especifica na evolução, mais complementos são necessários para atender a essas especificidades, daí a razão pela qual a formação sintagmática é grandemente empregada.

Enfim, os neologismos revelam, além da motivação rotuladora das criações denominativa que objetivam nomear produtos, serviços, ideias, etc., as marcas das mudanças pelas quais passam a sociedade. Uma totalidade refletida em outra totalidade de menor complexidade.

\section{REFERÊNCIAS}

ABL - ACADEMIA BRASILEIRA DE LETRAS. Vocabulário ortográfico da língua portuguesa. 5. ed. São Paulo: Global, 2009.

ARAÚJO, M. de. Composição sintagmática, por siglas e acrônimos. In: RODRIGUES, A.; ALVES, I. M.a (org.). A construção morfológica da palavra. São Paulo: Contexto, 2015. p. 123-142.

AULETE, C. Aulete digital: o dicionário da língua portuguesa. Lexikon Editora Digital. Disponível em: www.aulete.com.br. Acesso em: 17 maio 2020.

CARONE, F. de B. Morfossintaxe. 9. ed. São Paulo: Ática: 2003.

\footnotetext{
${ }^{16}$ A parassinonímia ("para” = proximidade + "onímia” = nome) é a relação semântica estabelecida entre palavras quase sinônimas (morrer, perecer). Como a sinonímia absoluta é rara (ou, para alguns, inexistente), é mais comum a parassinonímia.

${ }^{17}$ As barras inclinadas indicam a variação.
} 
FERREIRA, A. B. de H. Dicionário Aurélio da língua portuguesa. Coordenação Marina Baird Ferreira e Margarida dos Anjos. 5. ed. Curitiba: Positivo, 2010.

GONÇALVES, C. A. Atuais tendências em formação de palavras. São Paulo: Contexto, 2016.

GONÇALVES, C. A. V.; ALMEIDA, M. L. L. de. Morfologia construcional: principais ideias, aplicação ao português e extensões necessárias. Alfa, São Paulo, v. 58, n. 1, p. 165-193, 2014.

GONÇALVES, C. A.; ANDRADE, K. E. A instabilidade categorial dos constituintes morfológicos: evidência a favor do continuum composição-derivação. DELTA, v. 32, n. 2, p. 261-294, 2016.

HARTMANN, R. R. K.; JAMES, G. Dictionary of Lexicography. London/New York: Routledge, 2001.

HOUAISS, A. Dicionário eletrônico Houaiss da língua portuguesa. Versão 3.0. Rio de Janeiro: Objetiva, 2009.

KRIEGER, M. da G. Do ensino da terminologia para tradutores: diretrizes básicas. Cadernos de Tradução, Florianópolis, v. 17, p. 189-206, 2006.

KRIEGER, M. da G. Dicionários escolares e ensino de língua materna. Revista Estudos Linguísticos, São Paulo, v. 41, n. 1, p. 169-180, jan./abr. 2012.

LINO, M. T. R. da F. Neologia e neonímia em língua portuguesa: critérios de identificação. Linha D’Água (Online), São Paulo, v. 32 , n. 3, p. 9-23, set./dez. 2019.

MARQUES, A. Especialista alerta para efeito rebote após fim de isolamento e critica uso de máscaras. Leiagora, Cuiabá, 15 abr. 2020. Disponível em: https://www.leiagora.com.br/noticia/79304/especialista-alerta-para-efeito-rebote-apos-fim-de-isolamento-ecritica-uso-de-mascaras. Acesso em: 20 abr. 2020.

MICHAELIS. Dicionário brasileiro da língua portuguesa. São Paulo: Melhoramentos, 2015. Disponível em: https://michaelis.uol.com.br/moderno-portugues/.

MONTEIRO-PLANTIN, R. S. Fraseologia: era uma vez um patinho feio no ensino de língua materna. Fortaleza: Imprensa Universitária, 2014.

ROCHA, L. C. de A. Estruturas morfológicas do português. 2. ed. São Paulo: WMF Martins Fontes, 2008.

RODRIGUES, A. S. Noções basilares sobre a morfologia e o léxico. In: RIO-TORTO, G. et al. (org.). Gramática derivacional do português. 2. ed. Coimbra: Imprensa da Universidade de Coimbra, 2016. p. 35-134.

SANTIAGO, M. S. Redes de palavras-chave para artigos de divulgação científica da medicina: uma proposta à luz da Terminologia. 2007. 151 f. Dissertação (Mestrado em Linguística Aplicada) - Programa de Pós-Graduação em Linguística Aplicada, Universidade do Vale do Rio dos Sinos, São Leopoldo, 2007.

\section{()(1) $\circledast$}

Recebido em 10 maio 2021. Aceito em 11/06/2021. 